\title{
Formation of Dioxin during Smoldering of CCA Treated Wood Char
}

\author{
NIGEL TAME, ERIC KENNEDY, and BOGDAN DLUGOGORSKI \\ Process Safety and Environment Protection Research Group \\ School of Engineering \\ The University of Newcastle \\ Callaghan, NSW 2308, Australia
}

\begin{abstract}
Production of dioxin during the smoldering of wood char containing chromated copper arsenate (CCA) was investigated. Preliminary results are presented for the smoldering of treated wood char at 300 and $400^{\circ} \mathrm{C}$, as a function of char loading, smoldering time and inlet oxygen concentrations. PCDF (mainly $\mathrm{Cl}_{4} \mathrm{DF}$ ) were the preferred products of smoldering, and the results indicate the dependence of PCDD/F yields on competing formation/dechlorination reactions. Early periods of mass conversion favored PCDD/F formation, but with increasing mass loss, dechlorination and decomposition began to dominate. While the amounts detected were not particularly high (maximum yield of $95 \mathrm{ng} \mathrm{TEQ} / \mathrm{kg}$ char oxidized), PCDD/F formation in wood fires may drastically increase with CCA combined with inorganic and organic chlorine contaminants.
\end{abstract}

KEYWORDS: smoldering, CCA, dioxin

\section{INTRODUCTION}

Preserving wood with metal-based solutions, in particular chromated copper arsenate (CCA), has provided the most popular method for protecting timber. In 1996 CCA accounted for the majority of the 850,000 $\mathrm{m}^{3}$ of treated timber produced in Australia [1].

CCA preservative is applied to virgin timber as an aqueous solution of $\mathrm{Cr}(\mathrm{VI}), \mathrm{Cu}(\mathrm{II})$ and As(V). CCA utilizes copper as a fungicide with a pentavalent arsenic biocide. Hexavalent chromium is incorporated to facilitate fixing of the other two species to the wood. Upon contact with the wood the $\mathrm{Cr}(\mathrm{VI})$ is reduced to $\mathrm{Cr}(\mathrm{III})$, by reacting with the lignin and carbohydrate polymers producing active sites. These active sites are then available for binding with other metal ions [2].

For protection in Australia, outdoor applications are required to have a minimum of $1 \%$ $(w / w)$ metal content. Installations exposed to marine borers; e.g., wharf pylons and oyster racks, can have concentrations over 2\% [3]. Domestic combustion of CCA-treated wood is not recommended as it results in the emission of arsenic compounds. However, with a lack of public education, or the difficult identification of impregnated wood after weathering and painting, burning of timber containing CCA is inevitable.

Impregnation with CCA is known to impart wood with a combustion property referred to as 'afterglow' [4]. After it is heated to the point of ignition, treated wood can sustain smoldering until the wood is completely consumed. Observations have noted this phenomenon occurring during grass fires which led to the destruction of treated fence posts and power poles $[4,5]$. Upon heating the posts ignite, but once the radiative heat of the fire front has passed, smoldering continues. Detailed investigations into the chemistry behind this behavior have not been published. However, the propensity to induce 
smoldering has been previously assessed for various inorganic species e.g.; $\mathrm{Na}$ and $\mathrm{K}$ [6,7], flame retardants [8], Pb, and Fe [8,9]. Since $\mathrm{Cr}(\mathrm{III})$ [9] and $\mathrm{Cu}(\mathrm{II})$ [10] have also been investigated, albeit in individual studies, it can be inferred that the CCA preservative would also promotes the smoldering behavior.

The combustion environment in smoldering fires favors the formation of products of incomplete combustion. In wood, these compounds are related to the thermal degradation of the lignin and holocellouse. Other species which are produced in trace levels under such conditions include polychlorinated dibenzo-p-dioxin and polychlorinated dibenzofurans (PCDD/F). These pollutants attract interest because of their bioaccumulative and highly carcinogenic properties.

PCDD/F have gained notoriety in recent history because of their classification as persistent organic pollutants (POP) which form in trace levels in all thermal processes. PCDD and PCDF are also referred to as dioxin and when substituted with chlorine in the 2,3,7, and 8 positions on the dioxin molecule, have carcinogenic and mutagenic characteristics. To allow comparison between the toxicities of different samples, the concentrations of the 17 2,3,7,8 isomers are weighed with toxicity equivalence factors (TEF). These quantities are assigned according to the particular congener's toxicity relative to that of the 2,3,7,8 tetrachlorodibenzo-p-dioxin (TCDD), which is set at 1 . These adjusted concentrations are then totaled to give the toxic equivalence (TEQ) of the sample. Another useful expression of PCDD and PCDF data is the distribution of congeners or level of chlorination (homologue groups). Such dioxin 'fingerprints' are characteristic of certain processes and therefore useful in eliciting information on the particular formation pathway.

Smaller contributions in dioxin inventories are presently gaining significance as advances in process technology begin to reduce the impact of traditional major dioxin sources, waste incineration and iron ore sintering. As such, domestic and open burning of wood and waste-wood refuse has been cited as an important PCDD/F source [11]. Technologies that reduce industrial emissions cannot be applied to processes such as backyard burning and open fires, in which heterogeneous fuels and poor combustion conditions are inherent.

A review article published recently by Lavric, et a.l [12] highlights the uncertainty in data for the solid and gaseous emissions of dioxin from wood combustion. Furthermore, conclusions that are derived from incineration experiments, may not necessarily extrapolate to fire conditions. Emissions of dioxin from incineration seem to be dependant on the temperature history of fly ash during post-combustion treatment [12]. However, rapid quenching of the product gases is likely in fires, and fly ash is not a common occurrence. These characteristics may limit the formation potential of dioxin in fires to the solid fuel phase.

In fires, PCDD/F are likely to be destroyed in the flames, with some recombination in the cooling gas and soot emissions [13]. It is more probable that PCDD and PCDF are released during pre-ignition oxidative pyrolysis or smoldering. These hypotheses are supported by the results of Wevers et al. [14] where the burnout stage of a pine/hardwood mixture exhibited a greater tendency for dioxin emission than the preceding ignition and flaming stages. These results were further confirmed in the burning of household refuse by Lemiuex et al. [15]. Other recent studies have shown that, the presence of the preservative CCA in pine, dramatically increased the ash dioxin concentration in the ash 
under fire conditions [16]. The enhanced formation was observed during the burnout of the wood char, after cessation of the flames.

It is clear from the literature that, contaminants in waste wood enhance the yield of PCDD/F during thermal treatment [12]. Therefore it is of considerable importance to relate the chemistry of timber fires to the mechanisms of dioxin formation, and ascertain the role of organic and inorganic contaminants common in waste-wood streams. Resins, plastics and pesticides could contribute to dioxin formation in wood fires [17-19] by supplying precursor molecules, additional chlorine sources and metal catalysts. The external addition of chlorine to wood is of particular importance as natural wood otherwise contains very low levels, which limits the PCDD/F-formation potential. Inorganic compounds containing $\mathrm{Cu}$ and $\mathrm{Fe}$ are known to promote various steps in the formation mechanism of PCDD and PCDF [20]. Cu(II), in particular, has been widely studied for its ability to facilitate chlorination of the dibenzofuran molecule [21], the condensation of chlorophenols to yield PCDD and PCDF [22] and formation from the combination of carbon, oxygen and chlorine (de novo synthesis). The so-called de novo formation is generally considered to be the production of dioxin as by-products of the oxidation of a carbonaceous matrix [23]. It is generally accepted that PCDD are the result of the coupling of chlorophenols (precursors), while PCDF are predominantly the product of the chlorination of the dibenzofuran parent molecule. The overall mechanism for dioxin formation include the dechlorination/decomposition reactions, which have been shown to compete at varying degrees as a function of temperature and oxygen content [20].

The current study intends to focus on the formation of dioxin as a function of carbon burnout for CCA-impregnated wood char. Here we present the measurements, for chars exposed to varying temperature and oxygen concentrations. Oxygen levels were selected to represent air and oxygen-starved atmospheres. The process of smoldering is controlled by the rate at which oxygen is delivered to the active char surface. The smoldering of CCA-treated wood was studied by flowing a mixture through a fixed bed of fine char particles. This approach simulates the slow burnout of impregnated char that is sustained by sufficient heat insulation, after flaming conditions have ceased. The system intends to represent the conditions in a charred log, the ash residues in a domestic heater, stove or burn barrel, or the open burning of waste wood. It is proposed that the CCA aids the dioxin formation in two ways; firstly, by enhancing the smoldering tendency of wood, thereby increasing the oxidation that drives de novo synthesis (at 250 to $400^{\circ} \mathrm{C}$ [23]), and secondly, by providing $\mathrm{Cu}(\mathrm{II})$, a compound that is a known catalyst in the formation mechanism.

\section{EXPERIMENTAL}

\section{Apparatus}

Char samples were annealed in a borosilicate glass reactor which was housed in a gas chromatograph oven. Two thermocouples were placed near the reactor to allow the oven temperature to be monitored. Mass flow controllers manipulated the flow rate of $\mathrm{N}_{2}$ and $\mathrm{O}_{2}$ fed to the system. Gaseous products leaving the reactor passed through an adsorbent cartridge packed with XAD2 to collect the organic analytes. A glycol solution $\left(-10^{\circ} \mathrm{C}\right)$ circulating in the jacket of the cartridge served to trap any condensable product species. 


\section{Materials}

A CCA-treated sample of Pinus radiata was obtained from a local supplier. The chemical characteristics of the timber sample have been published elsewhere [16]. $\mathrm{O}_{2}$ and $\mathrm{N}_{2}$ (Linde) used in the annealing experiments were of $99.999 \%$ purity. GC residue-analysis grade solvents were used in sample collection and preparation for PCDD/F analysis. The solvents were purchased from Omnisolv (EM Science, Germany). The ${ }^{13} \mathrm{C}$ mass labeled standards used for quantifying PCDD/F were supplied by Wellington Laboratories (Canada).

\section{Methods}

Only char containing CCA was used for dioxin tests since previous experiments found that untreated pine yielded insignificant levels under similar conditions. The method for preparing the char sample from the original wood has been described in detail elsewhere $[16,19]$. Briefly, as-received timber lengths were shredded and dried in an inert atmosphere. Chips were ignited under the irradiance of a cone calorimeter and exposed until cessation of flaming combustion. The yield of char was $18 \%$ of the original timber mass. Char samples were cooled in ambient conditions and the residue was milled and sieved to less than $125 \mu \mathrm{m}$. The impregnated char was soxhlet extracted 3 times in toluene to remove PCDD/F, followed by extraction in acetone to remove any residual toluene. The solvent was allowed to evaporate while stored under vacuum in a desiccator.

A known mass of char was loaded vertically into the reactor between plugs of glass wool. The glass wool was positioned around the inlet in such a way as to encourage dispersion and uniform flow of gas up into the entire cross section of the char. Prior to heating, the reactor was purged for 30 min under a $\mathrm{N}_{2}$ flow of $180 \mathrm{~cm}^{3} / \mathrm{min}$. Purging was continued for a further 15 min once the desired temperature was achieved. This allowed the reactor charge to reach thermal equilibrium before the start of oxidation. The oxygen flow was then initiated, to commence the experimental period. Oxygen concentrations of 10 and $21 \%$ combined with specific time periods were used to control the level of char conversion. The total gas flow was kept constant at $200 \mathrm{~cm}^{3} / \mathrm{min}$. The ratios of $\mathrm{N}_{2}$ to $\mathrm{O}_{2}$ in the input streams were confirmed with gas chromatography. The experimental program undertaken is outlined in Table 1.

Analysis for PCDD/F involved extracting the residual solid from the reactor along with the XAD from the adsorbent trap. All sample surfaces were thoroughly rinsed with acetone and dichloromethane and the rinses added to the sample after extraction. Prior to extraction ${ }^{13} \mathrm{C}$ labeled surrogate standard was added to the sample. An automated soxhlet unit (Buchi, Switzerland) was charged with a mixture of acetone:dichloromethane (50:50) to extract the analytes. Details of the subsequent preparation steps have been published previously [16]. Final analysis of the samples was conducted at the National Measurement Institute (NMI) - Pymble (Sydney, Australia). Samples were run on a Finnegan MAT 95 XL high resolution gas chromatograph/ high resolution mass spectrometer (HRGC/HRMS) with a mass resolution of 10,000.

To minimize contamination between experiments, the following procedure was adopted: All glassware was rinsed with toluene, hexane and acetone before soaking in detergent. The washed apparatus was then annealed in a furnace at $450^{\circ} \mathrm{C}$ for $2 \mathrm{~h}$, as an attempt to evaporate residual PCDD/F. Glassware was then used for the next experiment after a final rinse with acetone and dichloromethane. 
Table 1. Experimental program.

\begin{tabular}{ccccc}
\hline Exp no. & $\begin{array}{c}\mathbf{T} \\
\left({ }^{\circ} \mathbf{C}\right)\end{array}$ & $\begin{array}{c}\mathbf{m}_{\mathbf{i}}{ }^{\mathbf{a}} \\
(\mathbf{g})\end{array}$ & $\begin{array}{c}\mathbf{O}_{2} \\
(\mathbf{\%})\end{array}$ & $\begin{array}{c}\text { Time } \\
(\mathbf{m i n})\end{array}$ \\
\hline 1 & 300 & 3.1 & 10 & 40 \\
2 & 300 & 3.1 & 10 & 150 \\
3 & 300 & 3.1 & 10 & 240 \\
4 & 300 & 3.1 & 10 & 360 \\
5 & 300 & 1.5 & 21 & 120 \\
6 & 400 & 3.1 & 10 & 40 \\
7 & 400 & 3.1 & 10 & 150 \\
8 & 400 & 3.1 & 10 & 240 \\
9 & 400 & 3.1 & 10 & 360 \\
10 & 400 & 3.1 & 21 & 40 \\
11 & 400 & 1.5 & 21 & 120 \\
\hline
\end{tabular}

${ }^{\mathrm{a}} \mathrm{m}_{\mathrm{i}}=$ initial char mass

\section{RESULTS AND DISCUSSION}

The results from the experiments are summarized in Table 2. The term 'fraction of mass loss' refers to the amount of char lost during the given experimental time relative to the initial sample mass. The dioxin data is expressed as the yield per $\mathrm{kg}$ of char oxidized as well as independently of initial mass or the mass loss of the specimen; i.e., as the quantity that was detected in the samples. Results are presented as total $\mathrm{Cl}_{4}$ to $\mathrm{Cl}_{8} \mathrm{DD} / \mathrm{F}$, as well as the TEQ of the 2,3,7,8 isomers quantified. The contribution made by $\mathrm{Cl}_{4} \mathrm{DF}$ (the most abundant homologue group in all samples) is given as a fraction of the total amount. The greatest PCDD/F yield was observed for experiment 2 (Table 2), which corresponded to $2600 \mathrm{ng} / \mathrm{kg}$ char oxidized. Expressed as a toxic equivalence, the yield was $95 \mathrm{ng}$ TEQ $/ \mathrm{kg}$ char oxidized. Total amounts of PCDD/F (pg formed) for experiments of $3.1 \mathrm{~g}$ char heated in $10 \% \mathrm{O}_{2}$ (experiments 1,2,3,4,6,7,8,9) are represented in Fig. 1 as a function of the smoldering time.

Figure 1 exhibits the quantities of dioxin formed from the char as time increases. The fractional mass loss trends are also included for comparison. Flattening of the mass loss over time is indicated for each of the given temperatures, at approximately 0.80 at $300^{\circ} \mathrm{C}$ and 0.93 for $400^{\circ} \mathrm{C}$. 
Table 2. Summary of PCDD/F data.

\begin{tabular}{|c|c|c|c|c|c|c|c|}
\hline \multirow[b]{2}{*}{$\begin{array}{c}\text { Exp } \\
\text { no. }\end{array}$} & \multirow{2}{*}{$\begin{array}{c}\text { fraction of } \\
\text { mass loss } \\
(\text { db })^{\mathbf{a}}\end{array}$} & \multicolumn{2}{|c|}{$\begin{array}{l}\Sigma \mathrm{Cl}_{4} \text { to } \\
\mathrm{Cl}_{8} \mathrm{DD} / \mathrm{F} \\
\text { formed }\end{array}$} & \multicolumn{2}{|c|}{$\begin{array}{l}\Sigma \mathrm{Cl}_{4} \text { to } \\
\mathrm{Cl}_{8} \mathrm{DD} / \mathrm{F} \\
\text { yield }\end{array}$} & \multirow[b]{2}{*}{$\begin{array}{l}\text { PCDD: } \\
\text { PCDF }\end{array}$} & \multirow{2}{*}{$\begin{array}{c}\mathrm{Cl}_{4} \mathrm{DF} \\
\text { fraction } \\
\text { of total }\end{array}$} \\
\hline & & pg & $\begin{array}{c}\text { pg } \\
\text { TEQ } \\
\end{array}$ & $\mathbf{n g} / \mathbf{k g}^{\mathbf{b}}$ & ng TEQ/kg & & \\
\hline 1 & 0.31 & 1300 & 22 & 1400 & 23 & 0.478 & 0.42 \\
\hline 2 & 0.65 & 5300 & 190 & 2600 & 95 & 0.147 & 0.40 \\
\hline 3 & 0.79 & 4200 & 100 & 550 & 40 & 0.176 & 0.55 \\
\hline 4 & 0.80 & 790 & 25 & 320 & 10 & 0.252 & 0.54 \\
\hline 5 & 0.92 & 2300 & 54 & 1700 & 47 & 0.076 & 0.57 \\
\hline 6 & 0.37 & 630 & 18 & 540 & 15 & 0.169 & 0.65 \\
\hline 7 & 0.65 & 3400 & 45 & 1700 & 23 & 0.233 & 0.68 \\
\hline 8 & 0.90 & 2300 & 55 & 790 & 19 & 0.103 & 0.76 \\
\hline 9 & 0.93 & 1600 & 34 & 550 & 12 & 0.058 & 0.78 \\
\hline 10 & 0.58 & 1700 & 27 & 960 & 12 & 0.087 & 0.78 \\
\hline 11 & 0.96 & 1100 & 21 & 740 & 14 & 0.048 & 0.71 \\
\hline
\end{tabular}

${ }^{a}$ dry basis, ${ }^{b}$ kg refers to kg of char oxidized.

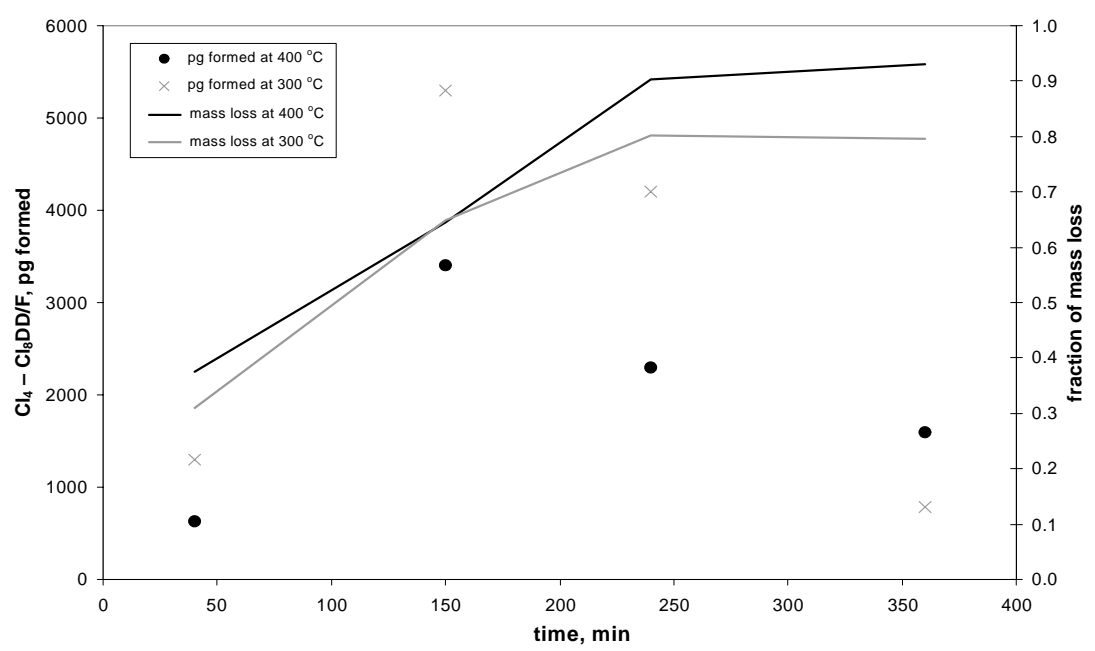

Fig. 1. $\mathrm{Cl}_{4}$ to $\mathrm{Cl}_{8} \mathrm{DD} / \mathrm{F}$ formed as a function of smoldering time.

For both temperatures, an initial increase in dioxin quantities is observed between 40 and $150 \mathrm{~min}$, followed by a decrease as smoldering time is continued, which is approximated 
to the period in leveling of the mass loss. It is also apparent that $300^{\circ} \mathrm{C}$ is a more optimal temperature than $400^{\circ} \mathrm{C}$ for the formation of PCDD/F, an observation which is consistent with those of other investigations [20,23]. These simple observations also support the hypothesis that the dioxin levels are the result of competing formation (chlorination) and decomposition/dechlorination reactions. This perspective is advanced with the consideration of Fig. 2.

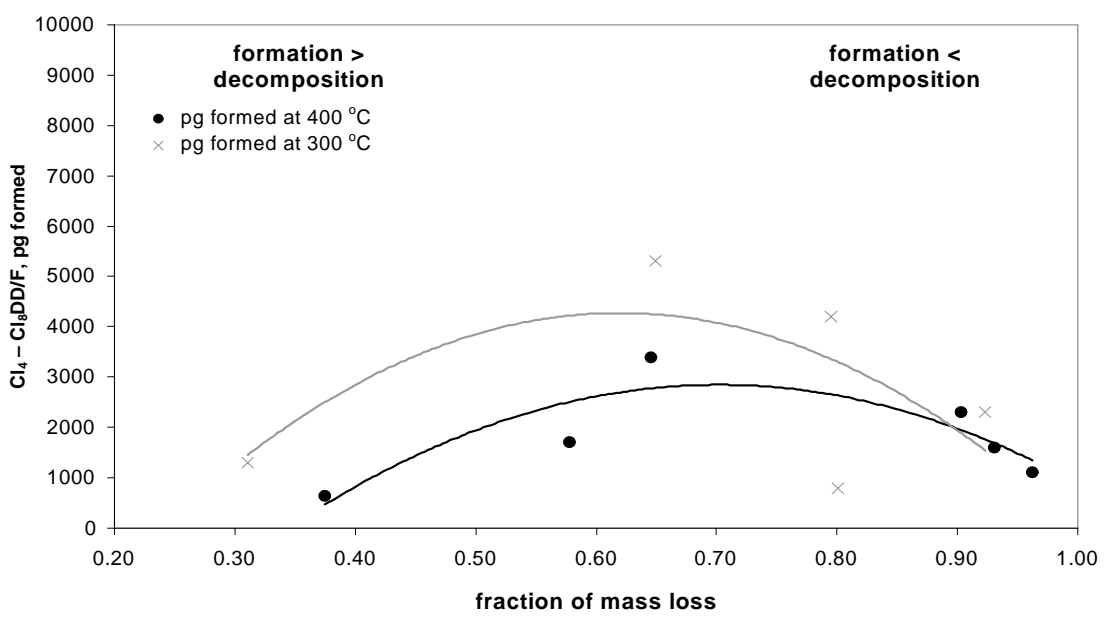

Fig. 2. $\mathrm{Cl}_{4}$ to $\mathrm{Cl}_{8} \mathrm{DD} / \mathrm{F}$ formed at $300^{\circ} \mathrm{C}$ and $400^{\circ} \mathrm{C}$ as a function of the fractional mass conversion.

Figure 2 exhibits the dioxin formation at 300 and $400^{\circ} \mathrm{C}$ as a function of the fractional mass conversion. The fractional mass conversion allows comparison of all the data for a given temperature, despite variation of oxygen content, time and char loading. Scatter is expected in the data, as certain combinations of these variables might be more favorable for PCDD/F formation or destruction. In particular, the point in Fig. 2. corresponding to experiment 4 (mass loss fraction of $0.79, \mathrm{Cl}_{4}-\mathrm{Cl}_{8} \mathrm{DD} / \mathrm{F}$ of $790 \mathrm{pg}$ ), appears to have yielded less PCDD and PCDF than expected. However, this corresponds to the mass loss plateau in Fig. 1 from 240 to 360 min when decomposition is dominant. Curves of best fit are included to help approximate trends in the data and to support the hypothesis that net dioxin formation is strongly dependant on char burnout.

Smoldering conversion of char occurs at greater rate at $400^{\circ} \mathrm{C}$, varying from 0.37 to 0.96 over the experiments conducted, while the fractional mass conversion at $300^{\circ} \mathrm{C}$ extends from 0.31 up to 0.92 . Higher conversion values for each temperature were obtained in $21 \% \mathrm{O}_{2}$ (experiments 5 and 11), allowing a greater proportion of mass loss than those experiments in Fig. $1\left(10 \% \mathrm{O}_{2}\right)$ and suggesting that a more aggressive oxidizing environment was required for the greater level of conversion. Continuing increase in the dioxin yield, however, was not the result of achieving a high degree of char conversion.

The nature of the trend in PCDD/F yields in Fig. 2 extend the data shown in Fig. 1 and support the contention that two controlling mechanisms take place simultaneously under smoldering conditions. The initial burn-off period suggests that chlorination is dominant, without the residence time that is required for the yield of $\mathrm{Cl}_{7}$ and $\mathrm{Cl}_{8} \mathrm{DF}$ to dramatically increase. For fractional mass losses of greater than 0.70, either dechlorination or oxidative decomposition of the parent molecule becomes controlling and the total $\mathrm{Cl}_{4}$ to $\mathrm{Cl}_{8} \mathrm{DD} / \mathrm{F}$ yield decreases. The mass conversion at which dioxin amounts start to decrease 
may coincide with the point that less $\mathrm{O}_{2}$ is being consumed after the smoldering front in the char has passed and the reactive fraction of the char has oxidized. The $\mathrm{O}_{2}$ may then be available to decompose PCDF remaining on the char surface. A comparison of the PCDF yield at the two temperatures confirms that $300^{\circ} \mathrm{C}$ is more desirable for formation (halogenation). The data can be analyzed further to highlight the selectivity towards the levels of PCDD/F chlorination as a function of mass conversion. These relationships are given in Fig. 3a for $300^{\circ} \mathrm{C}$ and Fig. $3 \mathrm{~b}$ for $400^{\circ} \mathrm{C}$.

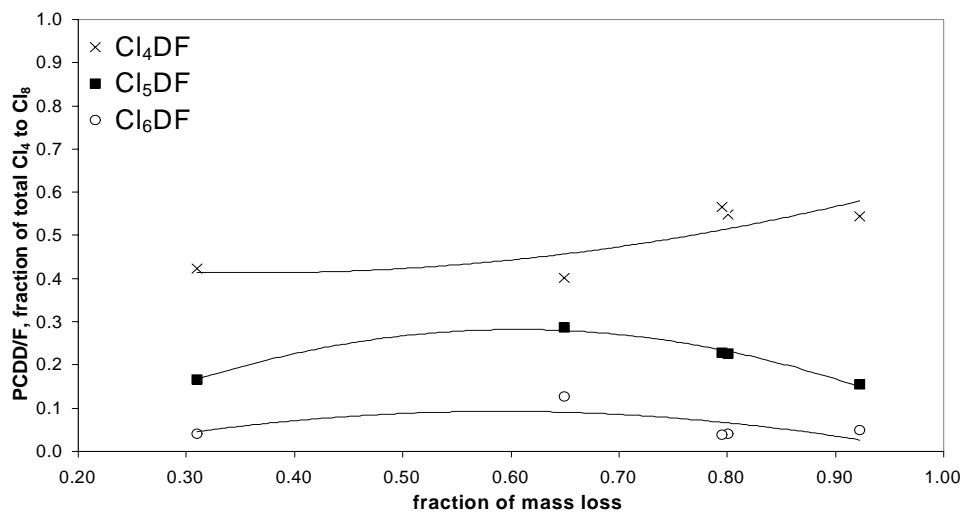

(a)

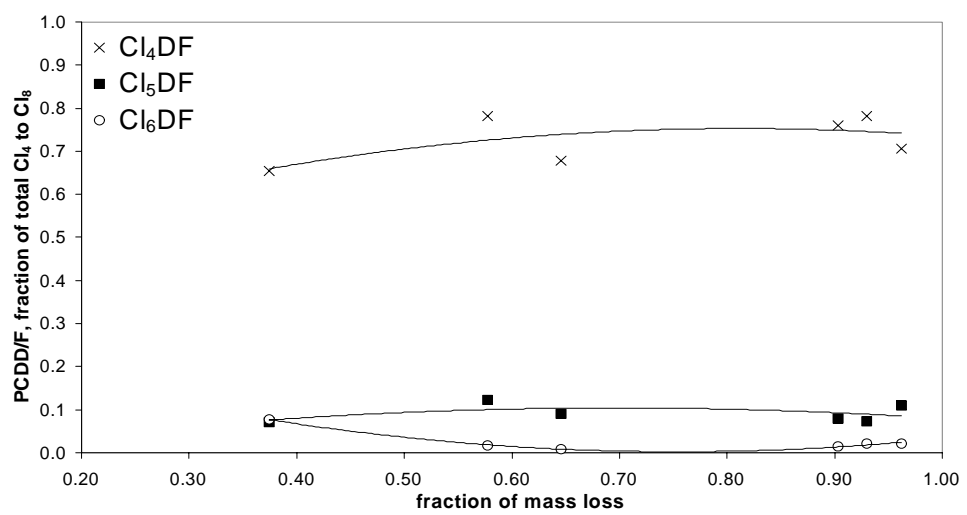

(b)

Fig. 3. Fractional contributions to the total amount of the $\mathrm{Cl}_{4}, \mathrm{Cl}_{5}$ and $\mathrm{Cl}_{6} \mathrm{DD} / \mathrm{F}$ homologues, as a function of mass loss fraction during smoldering.

(a) fraction of total pg formed at $300^{\circ} \mathrm{C}$ (b) fraction of total pg formed at $400^{\circ} \mathrm{C}$.

Selectivity as a function of mass conversion is directed towards the $\mathrm{Cl}_{4} \mathrm{DF}$ homologue at 300 and $400^{\circ} \mathrm{C}$. The fraction of $\mathrm{Cl}_{4} \mathrm{DF}$ in the total amount remains relatively constant at $400^{\circ} \mathrm{C}$, between 65 and $78 \%$ of the total, with increasing mass burnoutand decreasing the total amount of PCDD/F. The fact that the combined contributions of all homologues remain constant, while the total amount decreases, suggests the existence of a nonselective decomposition pathway. The experiments conducted at $300^{\circ} \mathrm{C}$ are more likely to show the effect of dechlorination under smoldering conditions, rather than oxidative destruction. At higher mass conversions, the contribution of $\mathrm{Cl}_{4} \mathrm{DF}$ at $300^{\circ} \mathrm{C}$ starts to 
increase as the fractions attributed to higher chlorinated groups $\left(\mathrm{Cl}_{5}\right.$ and $\left.\mathrm{Cl}_{6} \mathrm{DF}\right)$ decrease, as do the total PCDD/F amounts.

While the preliminary results presented here are not complete, and the net amounts of PCDD/F are not particularly high, several important conclusions may be drawn from the data. PCDD/F formation rates are known to increase from carbon matrices that have been 'aged'. This has previously been attributed to the increased aromatic structures in the carbon, and increased chlorination of the carbon macromolecule [13]. Under fire conditions, this would be the equivalent of char that has had the bulk of carbon oxidized slowly. Therefore burning off the more reactive carbon in the CCA char may yield a fuel that exhibits greater tendency to yield PCDD/F. Early experiments under less controlled conditions showed that CCA-treated char had the potential to produce dioxin amounts up to 1000 times those in Table 2. If the low level of native chlorine in the treated wood (ppm levels) is taken into consideration and bulk chlorine was available through further contamination of the CCA impregnated wood, e.g., as PVC, or salt from seawater, then the formation mechanism may not be as dominated by dechlorination. Future experiments should take these issues into account, along with assessing the reproducibility of the system.

\section{CONCLUSIONS}

A facility has been constructed to investigate the formation of PCDD/F during the smoldering of CCA-treated wood char. Observations were made on the basis of the amount of PCDD/F detected, and the selectivity towards $\mathrm{Cl}_{4} \mathrm{DF}$ isomers as function of mass conversion. Results indicate that the chlorination and decomposition of dioxin are the most dominant processes operating under smoldering conditions. Tentative trends showed that formation increased during initial mass conversion, but decreased thereafter, possibly due to oxidative attack on the parent molecule $\left(400^{\circ} \mathrm{C}\right)$ or dehalogenation $\left(300^{\circ} \mathrm{C}\right)$. The samples of greatest toxicity were produced at lower mass conversions rather than those from higher mass losses and extended residence times.

\section{REFERENCES}

[1] Greaves, H., “Treated Timber and the Environment,” Proc. Timber Design Conf., 1997, pp. 7.

[2] Humphrey, D.G., "The Chemistry of Chromated Copper Arsenate Wood Preservatives,” Reviews in Inorganic Chemistry, 22, pp. 1-40, (2002).

[3] AS/NZS 1604.1:2000, Specification of Preservative Treatment - Sawn and Round Timber, 2000.

[4] Dale, F.A. “Fence Posts and Fire,” CSIRO Forest Products Newsletter, No. 328, pp. 1-4, (1966).

[5] Evans, P.D., Beutel P., Cunningham, R.B., and Donnelly, C.F., "Fire Resistance of Preservative-treated Slash Pine Fence Posts,” Forest Products Journal, 44, Iss. 9, pp. 37-39, (1994).

[6] Waymack, B.E., "Smoldering Combustion of Biomass - Oxidation of Cellulose and Tobacco Chars," Proceedings of the NATAS Annual Conference on Thermal Analysis and Applications, 2002, pp. 598-604. 
[7] Kellog, D.S., Waymack, B.E., McRae, D.D., and Dwyer, R.W., "Smolder Rates of Thin Cellulosic Materials,” Journal of Fire Sciences, 15, pp. 390-403, (1997).

[8] Shafizadeh, F., Bradbury, A.G., DeGroot, W.F., and Aanerud, T.W., "Role of Inorganic Additives in the Smoldering Combustion of Cotton Cellulose," Industrial and Engineering Chemistry Product Research and Development, 21, pp. 97-101, (1982).

[9] McCarter, R.J., "Smoldering Combustion of Cotton and Rayon,” Journal of Consumer Product Flammability, 4, pp. 346-358, (1977).

[10] Ganga Devi, T., Kannan, M.P., and Richards, G.N., "Copper Catalysis in the Air Gasification of Cellulosic Chars,” Fuel, 69, pp. 1440-1447, (1990).

[11] Quaß, U., Fermann, M., and Bröker, G., "The European Dioxin Air Emission Inventory Project—Final Results,” Chemosphere, 54, pp. 1319-1327, (2004).

[12] Lavric, E.D., Konnov, A.A., and De Ruyck, J., "Dioxin Levels in Wood Combustion - A Review,” Biomass and Bioenergy, 26, pp. 115-145, (2004).

[13] Wikström, E., Ryan, S., Touati, A., Tabor, D., and Gullet, B.K., “Origin of Carbon in Polychlorinated Dioxins and Furans Formed During Sooting Combustion,” Environmental Science and Technology, 38, pp. 3778-3784, (2004).

[14] Wevers, M., De Fre, R., and Vanermen, G., "PCDD/F and PAH Emissions from Domestic Heating Appliances with Solid Fuel,” Organohalogen Compounds, 63, pp. 21-24, (2003).

[15] Lemieux, P.M., Gullet, B.K., Lutes, C.C., Winterrowd, C.K., and Winters, D.L., "Variables Affecting Emissions of PCDD/Fs from Uncontrolled Combustion of Household Waste in Barrels," Journal of the Air \& Waste Management Association, 53, Iss. 5, pp. 523-531, (2003).

[16] Tame, N.W., Dlugogorski, B.Z., and Kennedy, E.M., “Assessing the Influence of Experimental Parameters on Formation of PCDD/F from Ash Derived from Fires of CCA Treated Wood,” Environmental Science and Technology, 37, Iss. 18, pp. 4148-4156, (2003).

[17] Salthammer, T., Klip, H., Peek, R.D., and Marutsky, R., "Formation of Polychlorinated Dibenzo-p-dioxins (PCDD) and Polychlorinated Dibenzofurans (PCDF) During the Combustion of Impregnated Wood,” Chemosphere, 30, Iss. 11, pp. 2051-2060, (1995).

[18] Andersson, P., Blomqvist P., Rosell, L., and Simonson, M., "The Environmental Effect of Furniture," Interflam 2004 - Proceedings of the Tenth International Conference, 2004, pp. 1467-1478.

[19] Tame, N.W., Dlugogorski, B.Z., and Kennedy, E.M., "PCDD/F Formation in Flaming Combustion, Smoldering and Oxidative Pyrolysis of 'Eco-friendly' Treated Wood," Proceedings of the Combustion Institute, (accepted 27/04/04).

[20] Stanmore, B.R., "The Formation of Dioxins in Combustion Systems," Combustion and Flame, 136, pp. 398-427, (2004). 
[21] Ryu, J., Mulholland, J.A., and Chu, B., "Chlorination of Dibenzofuran and Dibenzo-p-dioxin Vapor by Copper (II) Chloride,” Chemosphere, 51, Iss. 10, pp. 1031-1039, (2003).

[22] Lomnicki, S., and Dellinger, B., "Formation of PCDD/F from the Pyrolysis of 2Chlorophenol on the Surface of Dispersed Copper Oxide Particles,” Proceedings of the Combustion Institute, 29 (Pt. 2), pp. 2463-2468, (2002).

[23] Huang, H., and Buekens, A., "De Novo Synthesis of Polychlorinated Dibenzo-pdioxins and Dibenzofurans Proposal of a Mechanistic Scheme," The Science of the Total Environment, 193, pp. 121-141, (1996). 
